\title{
La teoría funcional y la construcción pictórica de los conceptos en Ernst Cassirer
}

Gustavo Adolfo Esparza Urzúa Universidad Autónoma de Aguascalientes elprofeguz@gmail.com

\section{Introducción}

Uno de los aspectos centrales dentro de la filosofía de Ernst Cassirer es su propuesta de construir el conocimiento con base en conceptos funcionales en lugar de sustanciales. En su primera gran obra sistemática proponía una revisión de los avances de la lógica a la luz de los de las ciencias naturales. Para él, la química y la física se habían consolidado toda vez que, en lugar de concebir los objetos como realidades en sí, postularon un sistema de relaciones en el cual fuese posible determinar el sentido y significado de un fenómeno a través de la función. La propuesta del presente trabajo, sin embargo, no consiste en ofrecer un estudio comparativo entre los conceptos sustanciales y los funcionales, sino en profundizar en los medios por los cuales es posible la representación de la totalidad en los elementos singulares. Cassirer insistió en que, dada la característica constructiva del conocimiento, era necesario postular una teoría del concepto que se basara en la rela- 
ción antes que en la integración continua de elementos como copias de un objeto. Ahora la nueva tarea del análisis lógico consistirá en determinar las «formas» de las relaciones que un elemento guarda con un sistema teorético (1998c; 336-9).

Para lograr esto, el trabajo se dividirá en cuatro partes. La primera expondrá brevemente los términos en que plantea una distancia con un distanciamiento respecto de la lógica clásica e introduce la idea de una lógica funcional. La segunda explicará que las relaciones que guarda un concepto con el objeto, no dependen de la similitud entre los elementos que constituyen a la cosa en su dimensión física, sino a través de una representación pictórica o simbólica. En la tercera se desarrolla el modo en que la teoría de la función de Cassirer integra la teoría de la representación de Hertz. La cuarta explica la relación axiomática que se da entre los fenómenos naturales y los intelectuales, y se ofrece un esquema para explicar la representación. El conjunto permitirá concluir que la construcción de los conceptos depende de la relación de los miembros particulares con la totalidad de una serie que opera como fórmula general.

Los conceptos funcionales frente a los conceptos sustantivos

En 1910 Ernst Cassirer presentó su primer trabajo sistemático titulado Concepto sustancial y Concepto funcional $-S$ y F-, en donde no sólo reproducía una propuesta de sus maestros Herman Cohen y Paul Natorp al intentar explicar cómo es que las ciencias naturales construían sus conceptos, sino que además planteaba una nueva concepción de las tareas de la Función. Para Cassirer, «la evolución de la ciencia dentro de la última década» permitía configurar un «nuevo esquema (y tareas) de la lógica» (1953;3). La matemática, particularmente, 
era la ciencia que ofrecía un rico campo para investigar las relaciones entre los objetos naturales. En el planteamiento de la obra, el autor estipulaba un distanciamiento frente a la lógica, que por siglos se había ajustado a la visión aristotélica del concepto. Sobre este punto T.A. Ryckman comenta:

El «concepto genérico», de acuerdo con la lógica tradicional (de Aristóteles), se forma a través de la abstracción; de los datos de los individuos que entran en ella, los rasgos comunes pertenecientes a todos se aíslan. Considerando que el concepto de función, el cual «constituye el esquema general y el modelo según el cual el concepto moderno de la naturaleza ha sido moldeada en su desarrollo histórico progresista», se deriva de la nueva «lógica del concepto matemático de función» $(1991 ; 66)^{1}$.

El problema particular, según Cassirer, reside en que para Aristóteles el conocimiento se funda en la selección de las características esenciales del objeto, pero no existe garantía de que con ello sea posible construir un concepto, por ello agrega: «De hecho, no hay nada que nos asegure que las propiedades comunes que seleccionamos de cualquier colección arbitraria de objetos, incluya las características verdaderamente típicas que caracterizan y determinan la estructura total de los miembros de una serie» (Cassirer, 1953; 6-7) ${ }^{2}$.

Las traducciones del inglés son del autor.

Sería imprudente tomar sin más esta afirmación de que la lógica y la epistemología sustancial de Aristóteles (Metafísica, VII) no ofrece una solución al problema planteado por Cassirer, pero tampoco se puede discutir ampliamente en qué elementos puede ser corregida por la propuesta funcionalista y en qué efectivamente está en lo correcto. Para ofrecer un posible balance las investigaciones actuales sobre el problema del singular ofrecen una reinterpretación de este punto. Héctor Zagal (1999) considera que la anchínoia, synesis, euphyía están interrelacionadas y que su estudio ofrece una reinterpretación al conocimiento del singular, toda vez que a través de ellas se logra una conexión entre lo universal y lo particular, aunque acepta que el propio Aristóteles no ofreció una completa explicación de cómo es que se relacionan estas virtudes entre sí. Carlos Llano (1996), por su parte, plantea que lo «universal» y lo «singular» no pueden ser vistos 
Para Cassirer, es claro que una revisión comparativa entre la teoría clásica y las nuevas investigaciones científicas muestra que la formación de conceptos se ha desarrollado en términos funcionales antes que sustanciales; mientras que la teoría clásica propone una construcción de las «cosas-conceptos». Desde el siglo XVII hasta el xx, las ciencias naturales se han basado en una concepción de las «cosas-relaciones» (1953; 112-35). Él consideraba que la teoría del ser del estagirita condicionaba, a su vez, la concepción lógica y, por tanto, el conocimiento debía girar en torno a la sustancialidad de los objetos. El autor comenta sobre este punto:

[La] doctrina aristotélica de la formación del concepto llegó a tener una característica que se ha mantenido a pesar de las múltiples transformaciones que ha sufrido. La relación categórica fundamental de la cosa con sus propiedades sigue siendo desde entonces la perspectiva guía; mientras que las determinaciones relacionales sólo son consideradas en la medida en que pueden ser transformadas por algún tipo de mediación en propiedades de un sujeto o de una pluralidad de sujetos (Cassirer 1953; 8).

El principal problema, entonces, se deriva de la construcción de «cosas-conceptos» en lugar de «relación-conceptos» (Cassirer, 1953; 9), pues una visión sustancial no explica satisfactoriamente el vínculo entre lo singular y lo universal; aunque se propuso que la mente elabora conexiones psicológicas entre

como «bipolaridad» sino como «armonía complementaria», pues dado que lo substancial es el «ente primero», es posible pensar en un camino que permita entender que lo primero es, a la vez, universal. El autor acepta que no es posible una comprensión total del singular pero explica que los caminos de la prudencia y de la acción práctica nos aproximan a una comprensión universal de los hechos singulares. Insiste en que no se pretende discutir a fondo el tema, pero me parece que esta afirmación de que lo funcional ofrece un camino viable, no necesariamente cancela el camino presentado por Aristóteles, en todo caso, se presenta como una mejor alternativa. 
hechos y conceptos, apoyándose en palabras o signos, una asociación de esta naturaleza no ofrece una respuesta al modo en que los conceptos se construyen. Cassirer, para profundizar en este punto, se apoya en la construcción de las figuras geométricas como el cuadrado, el círculo, el rombo, el cubo, que no se apoyan de objetos físicos sino en un sistema de relaciones para su concepción. Para el filósofo «no existen cosas reales que coincidan precisamente con las definiciones geométricas» (Énfasis del autor) (Cassirer, 1953; 13).

Para contrastar este punto, se puede retomar el estudio de Eduardo Giovannini sobre Hilbert. El autor considera necesario distinguir que «en virtud de su origen epistemológico debe diferenciarse entre la matemática pura (aritmética, álgebra, análisis, teoría de números, teoría de funciones, etc.) y la matemática mixta, en donde se encuentran la geometría y la mecánica» (Giovannini, 2012; 30). Para Hilbert, según este autor, la construcción de conceptos geométricos no se desarrolla sólo por la experiencia sino que «las proposiciones básicas de la geometría elemental no son muy distintas de las proposiciones de la física en cuanto a que, en un sentido factual, formulan una multitud de "hechos del mundo exterior" » (Giovannini, 2012; 32), aunque no se debe entender a la geometría como una mera «descripción del espacio físico, sino sólo como una estructura conceptual o relacional susceptible de recibir diversas interpretaciones» (Giovannini, 2012; 33), por lo que diversas interpretaciones geométricas son posibles en tanto que las relaciones predicadas en los axiomas se cumplan.

El filósofo alemán, entonces, con recurrir a la matemática y la física propone un nuevo criterio desde el cual comprender la construcción de los conceptos, ya no se trata de copias pasivas de objetos, pretendiendo con ello una comunicación inmediata de la realidad. Ahora se trata de una mediación 
representativa; es decir, lo «individual no debe permanecer aislado sino que debe insertarse en una conexión en la que aparezca como miembro de una "estructura" lógica, teleológica o causal» (Cassirer, 1998a; 18). Entonces, el nuevo reto se encuentra en explicar cómo es que la relación de lo individual con la totalidad da paso al conocimiento o, en otros términos, cómo es que el concepto representa.

\section{El concepto y su carácter funcional: una teoría de la representación pictórica}

Para resolver la cuestión acerca de cómo se da la relación entre los elementos singulares que figuran en un concepto y cómo éste abarca la totalidad de la expresión del fenómeno, Cassirer (1953; 271-83) (1998a; 14-5) recurre a los trabajos de Hertz, para quien los objetos, en lugar de ser conocidos por su presencia directa, ofrecen señales (signos) que deben interpretarse. Con esto buscaba renunciar a un estudio directo de las cosas y en su lugar proponer un estudio de las representaciones mediadas simbólicamente. El propio Cassirer advierte este punto y plantea que los «conceptos fundamentales de cada ciencia, los medios con los cuales plantea sus cuestiones y formula sus soluciones, ya no aparecen como copias pasivas de un ser dado, sino como símbolos intelectuales creados por ella» (Cassirer, 1998a; 14).

Cuando en $S$ y $F$ se remarca la necesidad de suplantar los conceptos-cosas por los conceptos-relación el autor tiene en mente un tipo de representación homológica, en el sentido de Ibarra y Mormann (2000, 13-8); para ellos, Hertz, al proponer una relación simétrica entre consecuencias necesarias e intelectuales de las representaciones, postula una relación que no ofrece una copia de los objetos sino su aproximación axiomática. 
Con la teoría pictórica hertziana, Cassirer postulaba la búsqueda de una «Ley general» que ofreciera un sistema de referencia con el cual contrastar y dotar de sentido los casos particulares. El autor, con respecto a este punto, propone la siguiente metáfora apoyándose del ejercicio del matemático: «Cuando un matemático hace su fórmula más general, esto significa no sólo que busca mantener todos los casos especiales, sino también en ser capaz de deducirlos de la fórmula universal» (Cassirer, 1953; 19). Con una fórmula general, lo que el filósofo advierte es que ya no se trata de conocer de manera continua y sistemática todos los casos singulares para, de ellos, establecer una idea universal, sino una regla general que permita conectar a los particulares dentro de una Ley que contiene el criterio de relación. Para fundamentar la posibilidad de esta relación, el autor recurre a las investigaciones psicológicas que explican que al percibir un objeto, éste se presenta, en un primer momento, como evidencia sensible que permite advertir que algo se ha captado de manera múltiple (olor, color, tamaño, forma, tiempo, etcétera); en un segundo momento, el objeto se relaciona mentalmente para elaborar una idea general del conjunto de sensaciones captadas (Cassirer, 1953; 23-4). A partir de esta evidencia, lo que el filósofo ofrecerá es la idea de que los elementos percibidos forman parte de una serie y toman sentido sólo a la luz de una segunda serie que los unifica; a la primera serie la llamará «miembros de la serie», y a la segunda «forma de la serie», haciendo notar que todos los hechos particulares se encuentran interconectados por una Ley (Cassirer, 1953; 25-6).

El trabajo de T.A. Ryckman (1991) ofrece resultados fundamentales para profundizar en el concepto de función expuesto hasta aquí. Lo que el autor acentúa es que los elementos de la serie no tienen sentido en la medida en que pertenecen a una cadena sucesiva de datos, sino que justamente esa 
unión seriada cobra significado toda vez que los elementos se encuentran relacionados entre sí; no se trata de entender, explica Ryckman, una relación de causalidad, sino una relación de coordinación que permite que los elementos de una serie adquieran un significado construido o codependiente del conjunto previo. Por ello, a diferencia de Cohen, la Historia para Cassirer $(1944 ; 252-303)$ no es el criterio de relación o de presentación del problema, sino sólo un instrumento que permite entender el sentido que ocupa el miembro de la serie en la forma de esa misma serie ${ }^{3}$. Esta construcción del concepto, hace notar Ryckman, se encuentra enmarcada dentro de un «acto intuitivo» que presenta al objeto percibido siendo esto, tal es el primer paso para el desarrollo conceptual:

Cassirer argumentó que la intuición no es un sustrato autónomo o fuente independiente de conocimiento, sino que entra en el conocimiento sólo en la medida en que es «unificado» por el «pensamiento puro» en virtud de un «concepto de la serie», como un sistema de relaciones y dependencias funcionales. Zuordnung [Coordinación], para Cassirer, es entonces un «trascendental lógico» (en el sentido revisitado por el neokantismo de Marburgo) respecto a objetos constituidos caracterizados igualmente por la «ley» (Gesetz) de una serie, conectando sus miembros individuales, y la relación de dependencia o la comparación entre los miembros de series distintas, entre las que destacan la relación abstracta y no descriptiva de un sistema de conceptos (o teoría) con un colector de la percepción sensorial (Ryckman, 1991; 61).

Las relaciones intelectuales que Cassirer mantuvo con Herman Cohen tuvieron algunos pasajes tensos (ver Gawronsky, 1949; 6-23), sobre todo en lo concerniente a este punto. Mientras que el maestro consideraba la Historia como el criterio fundamental para la construcción de los conceptos, el discípulo postulaba que la ausencia de un análisis histórico podía ofrecer puertos seguros para el desarrollo del conocimiento, sin rechazar esta vía, postulaba una pluralidad de formas culturales como criterios para la construcción del conocimiento, en este punto se apoya en Natorp (ver Cassirer, 1998a; 61-75). Para profundizar en la relación entre Cassirer y Cohen (ver Moynahan, 2003). 
La percepción del objeto es el punto de partida que dota de sentido a la coordinación de la serie, pero ya no tendrá significado como parte de una integración infinitesimal sino que, explica Ryckman $(1991 ; 68)$, posee un sentido toda vez que se puede considerar como signo de la cosa. Hay que recordar que el signo es el elemento físico que permite la experiencia (la intuición) y su imagen correspondiente a la construcción intelectual que se forma de la coordinación de los axiomas geométricos (e históricos, epistémicos, lingüísticos, etcétera) con los objetos físicos. No se trata de seguir una coordinación puntual sino lógica, en donde las consecuencias de las imágenes sean las consecuencias de los hechos. Más adelante se analizará con mayor detalle este punto.

Este aspecto de la filosofía del neokantiano constituirá el fundamento en el que descansarán las formas simbólicas. Roberto González (2013; 41-56) explica que con la distinción entre el «signo» y la «imagen» (símbolo) es posible abarcar la dualidad que constituye al ser: física y espiritual. La separación de estos ámbitos ha constituido el gran problema metafísico dentro de la filosofía, de lo que se trata es de elaborar una metodología que permita entenderlas como dos facetas del ser (Cassirer, 1998a; 12-5).

Para Fritz Kaufmann (1949) la filosofía de Cassirer se interesa en conocer los hechos físicos del mundo y cómo es que se construyen conceptos a partir de las «experiencias» que obtenemos de los objetos. Este resultado no se opone a la correlación entre el objeto físico y la imagen o símbolo que se elabora, sino que a través de su vivencia (su experiencia), la imagen lograda se constituye como coordinación funcional entre ambos aspectos del conocimiento. Cassirer lo explica del siguiente modo: «La coordinación de la figura deducida con la figura original ya no se conecta con elementos que están realmente presen- 
tes y observables, sino elementos meramente intelectuales; se ha resuelto en una correlación puramente ideal» (énfasis del autor) $(1953 ; 83)$. Al establecer que la correlación ideal permeará la construcción de los conceptos, es necesario desarrollar los principios generales que sustentan que entre la imagen de un objeto y el objeto mismo no se requiere una relación detallada, sino una abstracción de los elementos.

\section{La construcción de la imagen del mundo}

Cassirer incluyó tanto la teoría del signo de Helmholtz como la pictórica de Hertz ${ }^{4}$ para fundamentar el carácter representativo de la función. El autor ofrece al menos dos elementos de partida para fundamentar esto anterior; primero fija que el «objeto no puede ser caracterizado como un mero "en sí" independiente de la categoría esenciales del conocimiento natural, sino que solamente de estas categorías, que constituyen su propia forma, puede ser descrito» (Cassirer, 1998a; 15); y segundo, el apoyo de una «teoría pictórica» $\mathrm{O}$ «teoría científica» ${ }^{5}$ de Hertz que puede describirse ampliamente en los siguientes términos:

Las imágenes o representaciones mentales de las que habla Hertz no son representaciones o copias de los objetos externos en el papel, en el lienzo, etc. Por el contrario, estas imágenes son representaciones internas o «intelectuales». Ello significa que la semejanza o parecido

Cassirer (1998d; 33-145) ofrecerá de modo posterior un estudio histórico-sistemático en el último volumen de El Problema del Conocimiento.

Giovannini cita el siguiente pasaje de Hertz: «creamos para nosotros imágenes intelectuales [innere Scheinbilder] o símbolos de los objetos externos; y lo realizamos de tal modo que las consecuencias necesarias de las imágenes en el pensamiento siempre sean imágenes de las consecuencias necesarias en la naturaleza de los objetos presentados. Para que se cumpla este requisito, debe existir cierta correspondencia entre la naturaleza y nuestra mente [Geist]» (2012; 38). Se retoma la cita porque el propio Cassirer (1998a; 14) se apoya de ella en la introducción de la PSF. 
que estas imágenes o símbolos deben mantener con los objetos representados se limita al requisito básico recién mencionado: las consecuencias de las imágenes en el pensamiento deben ser, a su vez, imágenes de las consecuencias en la naturaleza. Las Bilder de Hertz no pretenden informarnos nada acerca de la «esencia» de los objetos o fenómenos externos, de cómo son en sí (Giovannini, 2012; 38).

Para Hertz no existe entre el objeto y la imagen una relación esencial, salvo la de cumplir con el axioma de «representación pictórica o simbólica», es decir, no se puede esperar otro elemento esencial de las imágenes más allá de ser «símbolos» de los objetos físicos.

El conjunto de estos elementos retomados por Cassirer (1998a, 14-5; 1998b, 70-1) tienen como propósito la construcción de una imagen del objeto; al plantearse la necesidad de conocer algo no se estará representando sustancialmente cada elemento del objeto sino sólo su forma. No considera al objeto como una representación esencial o suma de elementos singulares, para él, la construcción espacial, numérica y temporal ofrecen la comprensión simbólica del objeto:

Concepto y forma son sinónimos; se unen sin distinción en el significado de eidos. La diversidad sensible se ordena y se divide por ciertas formas espaciales, que aparecen en el mismo y se ejecutan a través de la diversidad como elementos permanentes. En estas formas poseemos el esquema fijado por la que captamos en el flujo de las cosas sensibles, un sistema de determinaciones inmutables, un reino de «ser eterno». Así, la forma geométrica se convierte a la vez en la expresión y la confirmación del tipo lógico (Cassirer, 1953; 68).

Lo que propone no es la conjunción continua de unidades separadas que se unen como el referente de un todo, sino que se 
postula la determinación recíproca y su unión dentro de un sistema de coordinación funcional en el sentido que Ryckman (1991) explica; es decir, a través de la postulación de un axioma general se propone la construcción de una imagen o símbolo que representa la relación de identidad entre el pensamiento y el objeto (ver Cassirer, 1975; 193).

Con este carácter axiomático, es posible adentrarse en la comprensión de todos los miembros singulares que constituyen la forma de la serie y se pueden conocer debido a esta coordinación que otorga significado a los elementos particulares. Aquella pretensión de considerar a la función como la totalidad de las partes, es suplantada por un carácter serial que ofrece sentido sólo en la medida en que el singular es visto como un integrante del conjunto del que es tomado. La integración $(\mathrm{A}+\mathrm{x})$, para Cassirer, no representa el modelo general que debía seguir una lógica funcional, sino en su lugar se debía replantear una relación con la forma $[\varphi(x)]$. Emily Grosholz resume esta propuesta del siguiente modo:

[El] concepto matemático o científico busca explicar y aclarar todo el contenido de los casos particulares mediante la exhibición de sus conexiones sistemáticas más profundas, las cuales se revelan por la ley que gobierna a esa serie. Así, a partir de la ecuación general de Descartes, $\mathrm{Ax}^{2}+\mathrm{By}^{2}+\mathrm{Cx}+\mathrm{Dy}+\mathrm{E}=0$, podemos obtener las secciones cónicas particulares (círculo, elipse, hipérbola), presentadas con una interrelación sistemática; en este modelo, a un concepto más universal corresponde mayor $-\mathrm{y}$ no menor-contenido; no es una imagen difusa ni una presentación esquemática, sino un principio de orden serial $(2011 ; 8)$.

S.G. Lofts $(2000 ; 40-46)$ ofrece un resultado similar a este punto anterior cuando explica que la función en Cassirer constituye el principio constructor de los conceptos que no se dan 
como elementos agregados de una característica, sino como relación funcional con una serie correspondiente. A través de la representación simbólica « $\varphi(x) »$ se ofrece una mejor comprensión, explica Lofts, de la propuesta de Cassirer. Se trata de un vínculo funcional y no una copia fragmentada en donde cada parte es el total; el significado está constituido en la serie y a partir de ella tiene sentido el singular.

Dentro de la lógica funcional, la construcción conceptual del mundo ofrece la posibilidad de integrar sintéticamente el conjunto total de experiencias del sujeto. Esto es posible porque dentro de un sistema de interacciones funcionales reunidas dentro del concepto, el significado se desprende de la «relacionalidad sistemática en la que se halla... no previamente ni fuera del mismo» (Cassirer, 2010; 84). Este sistema obtiene un criterio de «unidad» no por la suma de los particulares sino por la «conexión de lo particular mediante reglas y no un universal junto con o sobre lo particular» (Cassirer, 2010; 88). Se propone, por tanto, sustituir la expresión de la «cosa en sí» por la expresión de «contexto conforme a leyes» (Cassirer, 2010; 93).

La relación necesaria entre consecuencias intelectuales y naturales del mundo

La influencia de Hertz en la FFs de Cassirer es algo más que unas citas ocasionales ${ }^{6}$. A pesar de las pocas referencias abiertas que se incorporan en los trabajos, es claro que el sistema general de las funciones se basa en la propuesta de la mecánica hertziana. Conviene, por tanto, hacer una pausa y explicar con la debida extensión la influencia de la función de Hertz en Cassirer.

Cassirer, al menos dentro de la PSF, cita sólo en dos ocasiones a Hertz. La primera es en Cassirer (1998a; 14-6 y 26), la segunda, en Cassirer (1998b; 70-71), aunque sin hacer explícita la referencia y en PSF, III no se hace referencia a Hertz. 
El problema de la física y la metafísica constituyó un problema central de discusión a lo largo del siglo XIX. Rafael Alemañ explica que la protesta positivista que cuestionaba los esquemas metafísicos como absolutos, demandaba una teoría física que ofreciera «esquemas formales mediante los cuales organizar nuestras sensaciones, con suficiente poder predictivo para resultar de utilidad práctica al género humano» (Alemañ, 2008; 190); por ello, la física de Mach plantearía que la mecánica tendría que ser la base para la refundación de la teoría clásica proponiendo que sólo los elementos cinemáticos podían ofrecerse como plausibles. Hertz, años más tarde, propondrá que no sólo los elementos visuales serán los únicos necesarios para la fundación de la mecánica sino todos aquéllos de los cuales se pueda postular una relación lógica. Si, propone Rafael Alemañ (2008; 192-193), para entender el problema propuesto por Hertz, nuestras manos y sus pesos pueden ser considerados como objetos de estudio por parte de la mecánica al ser visibles, ¿cómo explicar que las estrellas se mueven y existen si nunca se ha visto su movimiento ni sentido su peso? Hertz, por tanto, concluye que no son objeto de estudio sólo aquellos fenómenos directamente visibles sino en los cuales operan «movimientos ocultos» (Alemañ, 2008; 193). Con este término se proponía desarrollar un sistema mecánico que dependiera de algo más que lo visible y que, en su lugar, se sujetara a un sistema de leyes del cual fuese posible la derivación de sus conductas esperables. Para lograrlo, había que determinar un axioma general que permitiera «investigar todas las consecuencias lógicas» que se pudieran desprender de aquél (Alemañ, 2008; 194).

Cassirer conoce los postulados de Hertz cuando todavía éstos se encontraban en pleno debate por parte de la comunidad física de su tiempo. Pero el filósofo estaba interesado 
en algo más que la teoría mecánica, había encontrado en la fundamentación un rico campo de análisis para el desarrollo de su teoría de las formas simbólicas. El interés de Cassirer se centraba en el desarrollo de un axioma general con el que pudiera derivar el conjunto de consecuencias lógicas de las acciones:

La auténtica y concreta totalidad del espíritu no ha de ser caracterizada desde el principio en una simple fórmula y entregada como ya conclusa, sino que se desarrolla y encuentra a sí misma sólo en el curso siempre progresivo del mismo análisis crítico. La extensión del ser espiritual no puede ser caracterizada y determinada de otro modo sino midiéndosela en este proceso (Cassirer, 1998a; 19).

La totalidad del espíritu no es vista como totalidad abarcante sino como totalidad referente, por lo que, en lugar de colocarse por encima de todas las direcciones como superadas y hacia donde el pensamiento debía dirigirse, se planteaba un «punto central unitario» del cual fuese posible determinar cada caso particular. A esta unidad Cassirer (1998a; 21) le llamará «forma interna» del lenguaje, mito, y ciencia que no se reduce a una mera integración de formas particulares, sino que constituye una expresión plural dentro del diverso campo de las formas posibles.

El primer volumen de la FFS se publicó en 1923 y el segundo en 1924. El pensamiento mítico constituía un reto central para la comprensión de aquella forma de la cual Cassirer se planteaba demostrar, pues si existía un axioma general que podía abarcar el conjunto de las expresiones espirituales, había que mostrar su forma interna y la conexión general que guardaba la expresión mítica dentro de una filosofía del conocimiento. Al comenzar su exposición sistemática, nue- 
vamente el neokantiano se apoya de Hertz en su fundamentación y explica que, aunque la ciencia se caracteriza por su capacidad distintiva entre los fenómenos y ofrece una clasificación sistemática de las diversas expresiones, el mito opera de modo contrario. La totalidad de expresiones representan mutaciones derivadas de una forma original con la cual cobran sentido y forma. El conjunto de expresiones espirituales, consideradas todas ellas como «mitológicas», mostraba que podían reunirse bajo un campo axiomático común y, por tanto, era posible ofrecer una interpretación coherente a un «sistema expresivo de conocimientos» (Cassirer, 1998b; 5188; 1998c; 61-127).

Con el estudio sobre el mito, Cassirer plantea que existe una lógica propia de formas no-científicas y, además, que a través de la teoría pictórica de Hertz se puede ofrecer una relación necesaria entre consecuencias intelectuales y naturales. Así, en PSF, ii advierte que de un estado general A no se puede esperar una consecuencia B si antes no se integra un concepto mediador que vincule a ambos:

Del estado global A, el pensamiento extrae un determinado factor $\alpha$ que enlaza con un factor $\beta$ en B. Y el hecho de que $\alpha$ y $\beta$ se encuentren en una relación «necesaria», en una relación de «causa» $y$ «efecto», de «condicionante» a "condicionado», no es algo sólo extraído pasivamente de una percepción dada o de una pluralidad de percepciones, sino que tiene que demostrarse creando la condición $\alpha$ e investigando luego el efecto que trae aparejado (Cassirer, 1998b; 70).

Dicha relación se puede crear a través de, por ejemplo, experimentos de laboratorio, planeaciones educativas, bosquejos de obras, etcétera. Pero en el caso de la filosofía, esta relación se logra exponiendo a cada forma en su individualidad y lue- 
go extrayendo sus consecuencias generales (Cassirer, 1998a; 21). Por ello, y a partir del conjunto logrado en los primeros dos tomos, la FFS, iii constituye una evaluación general del conocimiento ofreciéndose las formas lingüísticas y las mitológicas como parte del sistema de evaluación de contraste; es decir, a través de la reflexión de las formas lingüísticas y mitológicas La Fenomenología del conocimiento se propone «extraer la consecuencia sistemática, esforzándose por explicitar el nuevo concepto de "objeto" al que hemos llegado, en todo su alcance y en toda su riqueza de posibilidades de configuración» (énfasis del autor) (Cassirer, 1998c; 7). Para él, entonces, la relación filosofía y mundo constituye más que una suposición o idealización de las formas; éstas, en lugar de ser objetos irreales, se plantean como objetos posibles que no necesariamente implican una ruptura con los hechos reales (ver Cassirer, 2012; 90-98).

Especialmente ilustrativo sobre este problema resulta el trabajo de Thomas Mormann (2014), quien explica que la filosofía de la ciencia desarrollada por Cassirer tiene como objeto la comprensión de las relaciones ideales entre los objetos físicos del mundo y sus construcciones intelectuales. Para Mormann, el conocimiento no puede reducirse a una relación de copia o de sustitución, sino a una relación funcional en la que el objeto percibido, en lugar de representar uno a uno, representa de manera ideal la conexión entre la física como ciencia de los fenómenos empíricos y la Matemática como ciencia de las relaciones intelectuales puras. El propio filósofo alemán ya había representado su sistema de pensamiento como «idealista», pero separándose del idealismo de Berkley y acercándose más a la propuesta por Kant. Para Cassirer, esta concepción: 
[...] no comienza con ninguna afirmación acerca de la naturaleza y la esencia de los objetos mismos; comienza con una investigación crítica sobre si los distintos modos de cognición mediante el cual diferentes clase de objetos -los objetos de la experiencia, los objetos de la ciencia, los objetos del pensamiento religioso o metafísico- son accesibles a nosotros (Cassirer, 1979; 69).

El neokantiano más adelante puntualizará que el conjunto de estos objetos se nos hacen comprensibles por medio de una relación general ideal que permite la vinculación de todos los elementos, no como entidades reducibles a un concepto abarcador, sino como manifestaciones diversas que encuentran «unidad de pensamiento simbólico» a través de una construcción formal de conceptos o una «coordinación funcional» (Ryckman, 1991; 58) que permite plantear que el grupo no se conforma como la similitud de los elementos, sino por medio de una categoría general previa que se ofrece como criterio de organización. Mormann (2014; 1-4), por ello, plantea que el «idealismo crítico» de Cassirer no se reduce a una pretendida conformación de la realidad a través de la mente, sino a una correlación entre los elementos empíricos a través de la física y su verificación ideal por medio de la matemática.

El idealismo que plantea Cassirer, por tanto, no se propone construir en la mente al mundo, ni explicar cómo es que éste es posible a través de la idealización. Él se propone una investigación de la lógica de la identidad entre el concepto y el fenómeno, o puesto en términos del propio autor:

«Pensar» $\mathrm{y}$ «ser» se conciben de tal manera que no sólo deban referirse o, en cierto sentido vago, deban corresponder uno a otro, sino que más bien coinciden: están en una relación estricta de identidad, ya que aquello que «es» el ser, aquello que significa según su pura 
esencia, sólo se deja captar por el pensamiento y verificar en él, y porque, inversamente, no hay pensar alguno que no se refiera a un ente determinado y unívoco como a su objeto (Cassirer, 1975; 190).

Retornando a la relación funcional, que por ahora ocupa el problema general del presente trabajo, se tiene el resumen que propone el filósofo:

[Formamos] «Imágenes virtuales internas o símbolos» de los objetos exteriores de tal modo que las consecuencias lógicamente necesarias de las imágenes sean siempre las imágenes de las consecuencias naturalmente necesarias de los objetos reproducidos (Cassirer, 1998a; 14).

Esta relación entre consecuencias naturales e intelectuales se puede comprender mejor si se apoya del esquema ofrecido por Ibarra y Mormann (2000; 14):

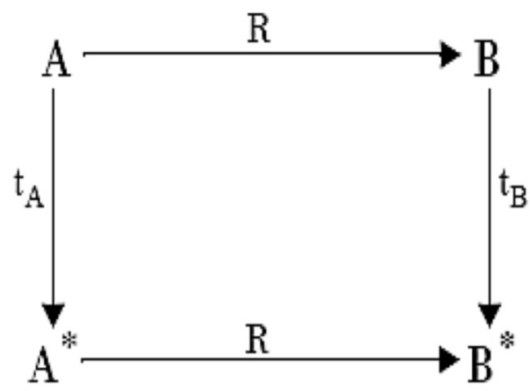

Esquema 2.1: Representación de la relación simétrica entre consecuencias intelectuales y naturales en Hertz según Ibarra-Mormann.

El esquema, siguiendo a sus autores, se puede leer del siguiente modo. En la parte izquierda $A{ }^{\circledR} A^{*}$, tA se interpreta como un proceso empírico que pasa de A hacia $A^{*}$ a través del estado tA. El paso, explican los autores, se representa por 
un proceso teórico que va de $B$ a $B^{\star}$ por $t B$ en donde éste es una relación lógica entre $\mathrm{B}$ y $\mathrm{B}^{*}$ que corresponde a la relación tA «naturalmente necesaria» entre A y B por R.

$\mathrm{Si}$, para entender mejor este esquema, se ofrece un ejemplo extraído de la Pedagogía escolar, se podrá aplicar mejor al análisis de la fFs de Cassirer. Supongamos que un alumno ingresa en cierto año a la universidad para estudiar medicina (A) siendo, en ese momento, incapaz de realizar intervenciones médicas, pero luego de finalizados sus estudios $\left(\mathrm{A}^{*}\right)$ tiene las habilidades necesarias para hacerlo. Aunque la primera tendencia sería decir que asistió a la universidad (B) no se puede determinar que todos los alumnos que asistieron al mismo tiempo sean capaces de hacer lo que el alumno puede hacer en $A^{*}$. En todo caso, habría que hacer explícita la relación entre $A^{*}$ y $B^{*}$ diciendo que el cumplimiento de un programa curricular (R), el cual plantea una serie de actividades y tareas de entrenamiento médico en diversos órdenes, es el que opera como el verdadero vínculo entre $A^{*}$ y $B^{*}$; por tanto, $\mathrm{R}$ es la función curricular que promueve el necesario desarrollo de habilidades médicas en el alumno.

En Cassirer, entonces, cada forma simbólica se corresponde lógicamente $(R)$ por un acto de vinculación intelectual entre el signo intuido de la cosa y el contexto funcional con el que se vincula. Así, por ejemplo, entre la intuición expresiva y el mundo de la percepción el mito se ofrece como R; entre la significación del objeto y el mundo teorético la ciencia es la relación entre ambos elementos del sistema.

Conclusiones

La lógica funcional propuesta por Cassirer plantea que la construcción de los conceptos debe adoptar un punto de vis- 
ta en el que las relaciones ideales que mantiene el fenómeno sea la fórmula general que dote de sentido a los miembros particulares de una serie. A través de la idealización de los vínculos que un objeto mantiene con su contexto, es posible la construcción de una imagen simbólica que ya no ofrece una visión sustancial del conocimiento, sino su aproximación formal. Una crítica del conocimiento busca un punto de vista universal a través del cual se pueda estudiar la relación existente entre los miembros individuales de esa totalidad: relación que sólo se comprende 1) una vez que se han investigado los fenómenos individualmente y 2 ) estableciendo entre todos ellos una unidad funcional común.

\section{Bibliografía}

Aristóteles. (1994). Metafísica. T. Calvo (trad.). Madrid: Gredos.

Alemañ, R. (2008). Geometría y Física: De Hertz a Einsten. Revista de la Sociedad Española de Historia de las Ciencias y de las Técnicas 68 (31), 189-208.

Cassirer, E. (2012). Antropología filosófica: una introducción a la filosofía de la cultura. E. Ímaz (trad.). México: FCE.

Cassirer, E. (2010). Filosofía Moral, Derecho y Metafísica: un diálogo con Axel Hägerstrom. R. Aramayo (trad.). Barcelona: Herder.

Cassirer, E. (1998a). Filosofía de las Formas Simbólicas, Vol. 1: El lenguaje. A. Morones (trad.). México: FCE.

Cassirer, E. (1998b). Filosofía de las Formas Simbólicas, Vol. 2: El pensamiento mitico. A. Morones (trad.). México: FCE.

Cassirer, E. (1998c). Filosofía de las Formas Simbólicas, Vol. 3: La fenomenología del conocimiento. A. Morones (trad.). México: FCE. 
Cassirer, E. (1998d). El problema del conocimiento en la filosofía de las ciencias modernas: de la Muerte de Hegel a nuestros dias, vol. IV. W. Roces (trad.). México: FCE.

Cassirer, E., (1979). Symbol, Myth and Culture: Essays and Lectures of Ernst Cassirer (1935-1945). D. P. Verene (edit.). New Haven: Yale University.

Cassirer, E. (1975). Esencia y efecto del concepto de símbolo. W. Roces (trad.). México: FCE.

Cassirer, E. (1953). Substance and Function E Einstein's Theory of Relativity. W. Swabey and M. Swabey (trad.). New York: Dover Publications.

Gawronsky, D. (1949). Ernst Cassirer: His Life and His Work.

En The philosophy of Ernst Cassirer. La Salle II: Open Court Publishing, 1-38.

Giovannini, E. (2012). «Una imagen de la realidad geométrica»: la concepción axiomática de la geometría de Hilbert a la luz de Bildtheorie de Heinrich Hertz. Crítica 131 (44), 27-53.

González, R. (2013). Renovación del humanismo y emancipación antropológica: hacia una metafísica del umbral a partir de la filosofía de las formas simbólicas. México: Fontamara.

Grosholz, E. (2011). El humanismo en Cassirer. La Gaceta del Fondo de Cultura Económica 492, 6-8.

Ibarra, A. \& Mormann, T. (2000). Una teoría combinatoria de la representación científica. Crítica 95 (XXXII), 3-46.

Kaufmann, F., (1949). Cassirer, Neo-Kantianism, and Phenomenology. U.S.A.: Evanston.

Llano, C. (1996). El conocimiento del singular, México: Cruz O. Lofts, S. (2000). A repetition of Modernity, New York: Suny Press.

Mormann, T. (2014). On the Vicissitudes of Idealism in 20th Century Philosophy of Science: The Case of Cassirer's Critical Idealism. Manuscrito en prensa. 
Moynahan, G. (2003). Hermann Cohen's Das Prinzip der infinitesimalmethode, Ernst Cassirer, and the Politics of Science in Wilhelmine Germany, Perspective on Science 1 (11), 35-75.

Ryckman, T. (1991). Conditio sine qua non? Zuordnung in the early epistemologies of Cassirer and Schlick. Synthese 88, 57-95.

Schilpp, P. (1949). The Philosophy of Ernst Cassirer. Evanston: The library of Living Philosophers.

Zagal, H. (1999). Sýnesis, euphyía y anchínoia en Aristóteles algunas habilidades para el conocimiento del singular. Anuario filosófico 63 (32), 129-148.

Resumen

En el presente trabajo se investiga la naturaleza de la representación en la teoría de la Función desarrollada por Ernst Cassirer. Se propone que las relaciones que mantiene un objeto y su posterior construcción pictórica ofrecen una solución al problema de las relaciones entre lo individual y lo universal; el concepto y el fenómeno. Se remarca que, como característica central de la función, la representación opera como una fórmula general que dota de sentido a los casos particulares de una serie. Hacia el final se ofrece una explicación esquemática que ilustra el modo en que se construyen las mediaciones pictóricas en el conocimiento.

Palabras clave: Cassirer, Teoría funcional, construcción conceptual, representación pictórica, Hertz.

\section{Abstract}

In this paper the nature of representation and Ernst Cassirer's functional theory are analyzed. It is shown that an object and 
its subsequent pictorial construction, offers a solution to the problem of relations among the individual and the universal; the concept and the phenomena. It is highlight that, as main feature of function, representation runs as general formula which gaves meaning to the individual cases members of a series. At the end it is offered an schematic explanation which illustrates how pictorial mediations are constructed in knowledge.

Key Words: Cassirer, functional theory, conceptual construction, pictorial representation, Hertz. 